\title{
LIMITACIONES DE LAS CLÁUSULAS CONTRACTUALES PARA DETERMINAR LA NATURALEZA JURÍDICA DE LA INFORMACIÓN Y PARA PROTEGER LOS SECRETOS EMPRESARIALES
}

NELSON REMOLINA ANGARITA* Y GABRIELA TAFUR NADER ${ }^{* *}$

\section{INTRODUCCIÓN}

La información es, entre otros, el activo más importante de muchas empresas y empresarios. Esta puede ser determinante del éxito de los negocios y del valor agregado que ofrecen a sus clientes y a la sociedad en general.

En ciertos casos, la información es la base de los modelos de negocios de muchas organizaciones y, sin duda, su valor se ha hecho más notorio en el contexto de la economía digital ${ }^{1}$. Por eso, la doctrina ha insistido en que "el debido cuidado en el tratamiento de la información, que asiste a la responsabilidad digital empresarial, se convertirá en una norma de facto ${ }^{2}$ para las empresas de este siglo que aspiran a ser protagonistas en su sector de negocio"”. (Destacamos. Nota al pie fuera del texto original).

\footnotetext{
* Doctor (PhD.) Summa Cum Laude en Ciencias Jurídicas por la Universidad Javeriana. Master of Laws, The London School of Economics and Political Sciences. Especialista en Derecho Comercial y Abogado de la Universidad de los Andes. Profesor asociado y director de la Especialización en Derecho Comercial de la Universidad de los Andes. Director del gecti (Grupo de Estudios en Internet, Comercio Electrónico, Telecomunicaciones e Informática) https://gecti.uniandes.edu.co/ y del Observatorio Ciro Angarita Barón sobre la protección de datos personales https://habeasdatacolombia.uniandes.edu.co/ de la Universidad de los Andes. Bogotá, D. C., Colombia. Correo electrónico: nremolin@ uniandes.edu.co. Fecha de recepción: 29 de septiembre de 2017. Fecha de aceptación: 30 de octubre de 2017. Para citar el artículo: Remolina Angarita, N.; Tafur Nader, G. "Limitaciones de las cláusulas contractuales para determinar la naturaleza jurídica de la información y para proteger los secretos empresariales", Revista La Propiedad Inmaterial n. ${ }^{\circ}$ 24, Universidad Externado de Colombia, julio-diciembre 2017, pp. 145-165. DOI: https://doi.org/10.18601/16571959.n24.07

** Estudiante de Derecho de la Universidad de los Andes. Coordinadora de la Especialización en Derecho Comercial de la Universidad de los Andes. Bogotá, D. C., Colombia. Correo electrónico: g.tafur10@uniandes.edu.co.

1 Suñol Lucea, A. El secreto empresarial. Un estudio del artículo 13 de la Ley de Competencia Desleal [impreso]. Pamplona: Thomson Reuters, 2009, p. 27. IsBn: 9788447031832.

2 Por norma de facto el autor se refiere a una norma consuetudinaria; en contraposición, a una norma creada por el Estado.

3 Cano Martínez, J. ¿Eres una empresa digitalmente responsable? [en línea]. Bogotá, 20 enero de 2016 [fecha de consulta 1. ${ }^{\circ}$ de septiembre de 2017]. Disponible en https:// www.linkedin.com/pulse/eres-una-empresa-digitalmente-responsable-jeimy-cano-ph-d-cfe
} 
En el campo empresarial, la información se encuentra dividida en ciertas categorías (libros y papeles del comerciante, los datos personales y los secretos empresariales, entre otras) que tienen diferentes características, distintos niveles de protección y que generan deberes particulares para quienes hacen uso de cada una.

Los secretos empresariales son parte de la información valiosa y estratégica de las organizaciones, en ellos inciden varias regulaciones que promueven su protección desde diferentes ámbitos, como, entre otras, la propiedad intelectual, el derecho de la competencia, el derecho penal y el derecho contractual. Todas estas regulaciones son complementarias y tienen objetivos comunes en algunos casos y diversos en otros.

Las estipulaciones contractuales, por su parte, han sido uno de los instrumentos más utilizados para tratar de proteger esa información. Normalmente, en ellas se establece que cierta información es considerada un secreto empresarial, y se pactan deberes de confidencialidad y limitaciones de uso. No obstante, en recientes fallos de la Superintendencia de Industria y Comercio se observa cómo diferentes actores, mediante el uso de cláusulas contractuales, han tratado de convertir información de cualquier tipo en secretos empresariales, a pesar de que esta no reúna los requisitos para tales efectos.

Con esto en mente, este texto tiene como propósito analizar los requisitos jurídicos para que cierta información alcance la categoría jurídica de secreto empresarial y mostrar cómo las cláusulas contractuales por sí solas no determinan la naturaleza jurídica de los secretos empresariales ni son suficientes para protegerlos. Se pretende lograr este objetivo a partir del estudio y las conclusiones de algunas sentencias de la Superintendencia de Industria y Comercio.

\section{DELIMITACIÓN TEMÁTICA Y REGULATORIA}

Dado que hay una amplia doctrina, jurisprudencia y regulación, tanto nacional como internacional, sobre la propiedad intelectual en general y los secretos empresariales en particular, parece importante advertir las limitaciones temáticas, regulatorias y geográficas de la presente investigación.

Temáticamente, es necesario precisar que este artículo se enfoca solo en analizar el concepto de los secretos empresariales, en los requisitos que la información debe cumplir para que adquiera el estatus de secreto empresarial y en las cláusulas contractuales como instrumento jurídico para alcanzar cierto grado de protección sobre dicha información.

Varios países cuentan con regulaciones generales sobre secretos empresariales ${ }^{4}$. Aunque se ha procurado armonizar internacionalmente algunas cuestiones sobre

4 Por ejemplo, los países de la Comunidad Andina que se rigen por la Decisión Andina 486 de 2000 y aquellos que forman parte del ADpIC (Acuerdo sobre los Aspectos de Propiedad Intelectual relacionados con el Comercio) o TRIPs, por sus siglas en inglés. En Tobón Franco, N. Secretos industriales, comerciales y know how. Bogotá: Editorial Jurídica Dike, 2008, pp. 63-72. ISBN: 9789588235998. Se puede consultar la normativa sobre los secretos empresariales. 
dicha temática, en la práctica cada Estado cuenta con normas que, en cierto grado, siguen dichos documentos internacionales, pero que al mismo tiempo están impregnadas de las particularidades sociales, políticas, culturales y jurídicas de cada uno. Adicionalmente, cada sistema jurídico nacional cuenta con diversos instrumentos jurídicos (constitucionales, administrativos, judiciales, entre otros) para proteger los secretos empresariales. Frente a esa situación, y pese a que los secretos empresariales tienen claras connotaciones internacionales, el análisis y las consideraciones de este texto se limitan a la regulación de la República de Colombia.

\section{DE LAS DIVERSAS CATEGORÍAS JURÍDICAS DE INFORMACIÓN EN LAS ORGANIZACIONES}

En una empresa puede reposar información privada ${ }^{5}$ o pública relacionada con sus actividades, sus negocios, sus empleados, sus clientes, sus ideas, sus invenciones, entre otros.

La información privada ${ }^{6}$ puede considerarse como el género del cual forman parte varias categorías, como las siguientes: comunicaciones privadas (art. 15 de la Constitución Política de Colombia-CP-), documentos privados (art. 15 de la CP), libros y papeles del comerciante (arts. 48 y siguientes del Código de Comercio), datos personales de los clientes -que pueden ser públicos, privados, semiprivados y sensibles (Ley 1581 de 2012)-, secretos empresariales (Decisión Andina 486 de 2000) e información privilegiada (art. 48 L. 222 de 1995).

El artículo 39 del acuerdo ADPIC se refiere a los secretos empresariales cuyo texto puede consultarse en https://www.wto.org/spanish/docs_s/legal_s/27-trips_04d_s.htm\#7. Ricardo Metke Méndez destaca que el "Acuerdo ADPIC establece para los países miembros de la OMC -Organización Mundial del Comercio- la obligación de incorporar en sus legislaciones internas las disposiciones que garanticen los estándares mínimos de protección de los derechos de propiedad intelectual, según los lineamientos que se prevén en el mismo acuerdo”. Ver: Metкe Méndez, R. Lecciones de propiedad industrial. Bogotá: Editorial Baker \& Mckenzie, 2001, p. 40. IsBN: 9789588075471.

5 Remolina, N. Tratamiento de datos personales: aproximación internacional y comentarios a la Ley 1581 de 2012. Bogotá: Legis, 2013, pp. 135-144. IsBn: 978-958-767-086-8.

6 En este espacio nos centramos en la información que usualmente está en poder de las empresas privadas, ya que en otros escenarios existen otras categorías de información catalogada por el regulador como reservada. Este es el caso a que se refiere, entre otras, la Ley 1621 de 2013. Allí explícitamente se considera como información reservada la siguiente: el Plan Nacional de Inteligencia (artículo 8); los documentos e información de los organismos de inteligencia y contrainteligencia (artículo 33). Para mayor precisión sobre la reserva en este tipo de documentos, nos remitimos a la sentencia C-540 de 2012 de la Corte Constitucional.

7 Ley 45 de 1990. Artículo 75. Información privilegiada. "Ninguna persona podrá, directamente o a través de interpuesta persona, realizar una o varias operaciones en el mercado de valores utilizando información privilegiada, so pena de las sanciones de que trata la letra a) del artículo 6. ${ }^{\circ}$ de la Ley 27 de 1990. Incurrirán en la misma sanción las personas que hayan recibido información privilegiada en ejercicio de sus funciones o los intermediarios de valores cuando aquellas o estos realicen alguna de las siguientes conductas: a) suministren dicha información a un tercero que no tiene derecho a recibirla, o b) en razón de dicha información aconsejen la adquisición o venta de un valor en el mercado. Para estos efectos se entenderá que es privilegiada aquella información de carácter concreto que no ha sido dada a conocer del público y que de haberlo sido la 
Los libros de comercio contienen información cuyo uso es frecuente en el escenario empresarial, por ejemplo, los libros de contabilidad y otros. No sobra recordar que, respecto a su alcance, el Consejo de Estado de la República de Colombia hizo la siguiente aclaración:

Dentro de los libros de comercio se encuentran los libros de contabilidad, en el entendido que son una especie de los primeros, pues si bien todos los libros de contabilidad son de comercio, no todos los libros de comercio son de contabilidad. Son libros de comercio -y no de contabilidad- el de actas de asamblea o junta de socios (C. Co., arts. 189, 195 y 431), el de registro de acciones (C. Co., arts. 195 y 406), el libro de registro de socios en la limitada (C. Co., art. 361), el libro de navegación o bitácora, etc. [...] [sic $]^{8}$.

No debe perderse de vista que cierta información que inicialmente se cataloga como privada, en determinadas ocasiones y escenarios adquiere la naturaleza de información pública. En este sentido, existe una especie de "relativismo" de la información privada en la medida que, dependiendo de dónde se recolecte, requerirá o no autorización de su dueño para divulgarse u obtenerse. Se presenta a continuación un ejemplo: los estados financieros son información privada según el artículo 15 de la Constitución Política de Colombia. No obstante, cuando una persona entrega a la Cámara de Comercio copia de su información contable para inscribirse en el Registro Único de Proponentes (RUP), cualquier persona puede acceder a ella, y, por tanto, no es un requisito obtener la autorización del titular de la información para tales efectos.

En términos generales, toda la información privada que llega a los registros públicos se convierte en pública, pero de manera relativa: si la información se solicita directamente al titular, se debe obtener con su autorización, pero si se recolecta del registro público, el consentimiento del titular de la información no es necesario. Entre los diferentes registros o bases de datos que por ley tienen la naturaleza de públicos están los siguientes: (1) Registro Único de Proponentes (RUP): "La información contenida en el registro es pública y su consulta será gratuita" ${ }^{10} ;(2)$ Registro Único Nacional de Tránsito (RUNT): "Toda la información contenida en el RUNT será de carácter público"11; (3) Sistema Integrado de Información sobre

habría tenido en cuenta un inversionista medianamente diligente y prudente al negociar los respectivos valores".

8 República de Colombia. Consejo de Estado. Sección cuarta. Sentencia del 9 de octubre de 1998. Consejero ponente, doctor Daniel Manrique Guzmán.

9 Cfr. Numeral 1 del artículo 9 del Decreto 1510 de 2013, "por el cual se reglamenta el Sistema de Compras y Contratación Pública”.

10 Artículo 6 de la Ley 1150 de 2007, “por medio de la cual se introducen medidas para la eficiencia y la transparencia en la Ley 80 de 1993 y se dictan otras disposiciones generales sobre la contratación con recursos públicos”. (Este artículo fue modificado por el Decreto 19 de 2012, artículo 221).

11 Artículo 9 de la Ley 769 de 2002, "por la cual se expide el Código Nacional de Tránsito Terrestre y se dictan otras disposiciones”. El RUNT comprende lo menos los 
las Multas y Sanciones por Infracciones de Tránsito (sIMIT): “Toda la información contenida en el sistema integrado de información sIMIT será de carácter público"12; (4) Registro sobre Garantías Mobiliarias ${ }^{13}$; según la Ley 1676 de 2013, "cualquier persona puede tener acceso al registro y solicitar copias de las inscripciones a través de Internet"; y (5) Registro Mercantil: el artículo 26 del Código de Comercio dice que dicho registro es público y "cualquier persona podrá examinar los libros en que fuere llevado, tomar anotaciones de los asientos o actos y obtener copia de [estos]".

Los documentos públicos, por su parte, son los creados, suscritos u otorgados "por el funcionario público en ejercicio de sus funciones o con su intervención. Así mismo, es público el documento otorgado por un particular en ejercicio de funciones públicas o con su intervención"14. Según la Corte Constitucional, la información pública "puede ser obtenida y ofrecida sin reserva alguna y sin importar si la misma es [el texto original dice sea] información general, privada o personal" 15 .

Para la Ley 1712 de 2014, es pública "toda información que un sujeto obligado genere, obtenga, adquiera o controle en su calidad de tal"16. Según el principio de transparencia, se presume pública toda la información en poder de los sujetos obligados definidos en la citada ley,

en consecuencia de lo cual dichos sujetos están en el deber de proporcionar y facilitar el acceso a [esta] en los términos más amplios posibles y a través de los medios y procedimientos que al efecto establezca la ley, excluyendo solo aquello que esté sujeto a las excepciones constitucionales y legales y bajo el cumplimiento de los requisitos establecidos en esta ley ${ }^{17}$.

Ahora bien, no toda la información que reposa en las entidades públicas es de acceso al público. En este sentido, la Ley 1712 de $2014^{18}$ señala que "los secretos comerciales, industriales y profesionales" que están en posesión, bajo control o custodia de las entidades públicas y demás sujetos obligados bajo dicha ley son con-

siguientes registros de información: “1. Registro Nacional de Automotores; 2. Registro Nacional de Conductores; 3. Registro Nacional de Empresas de Transporte Público y Privado; 4. Registro Nacional de Licencias de Tránsito; 5. Registro Nacional de Infracciones de Tránsito; 6. Registro Nacional de Centros de Enseñanza Automovilística; 7. Registro Nacional de Seguros; 8. Registro nacional de personas naturales o jurídicas, públicas o privadas que prestan servicios al sector público; 9. Registro Nacional de Remolques y Semirremolques". (Artículo 8).

12 Artículo 11 de la Ley 769 de 2002.

13 Creado mediante la Ley 1676 de 2013, “por la cual se promueve el acceso al crédito y se dictan normas sobre garantías mobiliarias". Entre la información que debe incorporarse en dicho registro están "Nombre, identificación y dirección física y electrónica del garante y del acreedor garantizado". (Artículo 41).

14 Cfr. Artículo 243 del Código General del Proceso (Ley 1564 de 2012).

15 Cfr. Corte Constitucional. Sentencias T-729 de 2002, C-336 de 2007 y C-334 de 2010 .

16 Cfr. Numeral b) del artículo 6 de la Ley 1712 de 2014.

17 Cfr. Artículo 3 de la Ley 1712 de 2014.

18 Por medio de la cual se crea la Ley de Transparencia y del Derecho de Acceso a la Información Pública Nacional y se dictan otras disposiciones. 
siderados como "información pública clasificada, cuyo acceso podrá ser rechazado o denegado de manera motivada y por escrito" ${ }^{19}$. Esta reserva sobre los secretos empresariales de las entidades públicas ha sido justificada y reiterada por la Corte Constitucional en diferentes sentencias ${ }^{20}$, entre las cuales se destaca la C-274 de 2013, en la que dicha Corporación expresó lo siguiente:

Uno de los límites admisibles al derecho de acceso a la información pública proviene de la necesidad de protección de otros derechos fundamentales que puedan ser afectados por el acceso y difusión de tal información. Tal es el caso de los datos personales que solo pertenecen a su titular y cuya divulgación podría afectar un derecho legítimo de este último, como el derecho a la intimidad, o de los secretos comerciales, industriales y profesionales, cuyo acceso puede afectar el ejercicio de las libertades económicas ${ }^{21}$.

Respecto del tratamiento ${ }^{22}$ de datos personales ${ }^{23}$ en las empresas, la regulación colombiana establece una serie de obligaciones que, en buena medida, dependen de la naturaleza jurídica del dato, que puede catalogarse como público ${ }^{24}$, privado ${ }^{25}$, semiprivado ${ }^{26}$ o sensible ${ }^{27}$. Los datos públicos, a su vez, son categorizados como datos públicos clasificados ${ }^{28} \mathrm{y}$ datos públicos reservados ${ }^{29}$.

Los datos personales públicos ${ }^{30}$ son, entre otros, los considerados como tales por la ley o aquellos que no son privados, semiprivados o sensibles. De conformidad con la Ley de Transparencia y del Derecho de Acceso a la Información Pública

19 Cfr. Literal c) del artículo 18 de la Ley 1712 de 2014.

20 Cfr. Por ejemplo, las siguientes sentencias de la Corte Constitucional: T-473 de 1992, T-1268 de 2001, T-511 de 2010, T-451 de 2011.

21 Cfr. Corte Constitucional. Sentencia C-274 de 2013. M. P.: María Victoria Calle Correa.

22 El tratamiento se refiere a "cualquier operación o conjunto de operaciones sobre datos personales, tales como la recolección, almacenamiento, uso, circulación o supresión” (Literal g del artículo 3 de la Ley 1581 de 2012).

$23 \mathrm{La}$ definición jurídica de dato personal está prevista en el literal c) del artículo 3 de la Ley 1581 de 2012 y en el literal e) del artículo 3 de la Ley 1266 de 2008.

24 Cfr. Numeral 2 del artículo 2.2.2.25.1.3 del Decreto 1074 de 2015.

25 Cfr. Literal h) del artículo 3 de la Ley 1266 de 2008.

26 Cfr. Literal g) del artículo 3 de la Ley 1266 de 2008.

27 Cfr. Artículo 5 de la Ley 1581 de 2012.

28 Cfr. Literal c) del artículo 6 de la Ley 1712 de 2014.

29 Cfr. Literal d) del artículo 6 de la Ley 1712 de 2014.

30 "Dato público. Es el dato que no sea semiprivado, privado o sensible. Son considerados datos públicos, entre otros, los datos relativos al estado civil de las personas, a su profesión u oficio y a su calidad de comerciante o de servidor público. Por su naturaleza, los datos públicos pueden estar contenidos, entre otros, en registros públicos, documentos públicos, gacetas y boletines oficiales y sentencias judiciales debidamente ejecutoriadas que no estén sometidas a reserva”. (Numeral 2 del artículo 2.2.2.25.1.3 del Decreto 1074 de 2015 - mayo 26-, por medio del cual se expide el Decreto Único Reglamentario del Sector Comercio, Industria y Turismo (Decreto 1377 de 2013, artículo 3. ${ }^{\circ}$ ). En la Ley 1266 de 2008 también fue definido como "dato calificado como tal según los mandatos de la ley o de la Constitución Política y todos aquellos que no sean semiprivados o privados, de conformidad con la presente ley. Son públicos, entre otros, los datos contenidos en documentos públicos, sentencias judiciales debidamente ejecutoriadas que no estén sometidos a reserva y los relativos al estado civil de las personas". (Literal f del artículo 3). 
Nacional ${ }^{31}$, se considera pública y no podrá ser reservada o limitada, sino por disposición constitucional o legal, toda información en posesión, bajo control o custodia de las entidades públicas y otros sujetos señalados por la Ley 1712 de $2014^{32}$.

Finalmente, los secretos empresariales conforman otra categoría jurídica de información muy valiosa en el entorno empresarial. Para que un secreto empresarial pueda considerarse como tal, debe cumplir unos presupuestos y requisitos previamente fijados por ley que la Superintendencia de Industria y Comercio ha sintetizado en los siguientes términos: "(1) verificarse la existencia de un conocimiento que verse sobre cosas, procedimientos, hechos, actividades y cuestiones similares; (2) que el conocimiento tenga carácter de reservado o privado -porque sus titulares han optado voluntariamente por no hacerlo accesible a terceros-; (3) que el secreto recaiga sobre procedimientos o experiencias industriales o comerciales, o esté relacionado con la actividad de la empresa o su parte organizativa; (4) que los titulares del secreto tengan voluntad e interés consciente de mantenerlo reservado, adoptando las medidas necesarias para ello; (5) que la información tenga un valor comercial, efectivo o potencial, siempre que su conocimiento, utilización o posesión permita una ganancia, ventaja económica o competitiva sobre aquellos que no la poseen o no la conocen; y (6) la información que repose en el Sistema Integral de Información del Mercado de Valores -SIMEV-, conformado por el Registro Nacional de Valores y Emisores -RNVE-, el Registro Nacional de Agentes del Mercado de Valores -RNAmv- y el Registro Nacional de Profesionales del Mercado de Valores -RnpmV-. Según el artículo 5.1.1.1.3 del Decreto 2555 de 2010, 'la información que repose en el sIMev será pública. En consecuencia,

31 Ley 1712 de 2014.

32 "Artículo 5.․ Corregido por el Decreto 1494 del 13 de julio de 2015, artículo 10. Ámbito de aplicación. Las disposiciones de esta ley serán aplicables a las siguientes personas en calidad de sujetos obligados:

a) Toda entidad pública, incluyendo las pertenecientes a todas las ramas del Poder Público, en todos los niveles de la estructura estatal, central o descentralizada por servicios o territorialmente, en los órdenes nacional, departamental, municipal y distrital.

b) Los órganos, organismos y entidades estatales independientes o autónomos y de control.

c) Las personas naturales y jurídicas, públicas o privadas, que presten función pública, que presten servicios públicos respecto de la información directamente relacionada con la prestación del servicio público.

d) Cualquier persona natural, jurídica o dependencia de persona jurídica que desempeñe función pública o de autoridad pública, respecto de la información directamente relacionada con el desempeño de su función.

e) Las empresas públicas creadas por ley, las empresas del Estado y sociedades en que este tenga participación.

f) Los partidos o movimientos políticos y los grupos significativos de ciudadanos.

g) Las entidades que administren instituciones parafiscales, fondos o recursos de naturaleza u origen público.

Las personas naturales o jurídicas que reciban o intermedien fondos o beneficios públicos territoriales y nacionales y no cumplan ninguno de los otros requisitos para ser considerados sujetos obligados solo deberán cumplir con la presente Ley respecto de aquella información que se produzca en relación con fondos públicos que reciban o intermedien”. 
cualquier persona podrá consultarla, observando las reglas que para el efecto se establecen en el presente decreto"'33.

A continuación, se hace referencia en detalle a otras cuestiones sobre esta información.

\section{DE LOS SECRETOS EMPRESARIALES: CONCEPTO Y REQUISITOS}

El artículo 260 de Decisión Andina 486 de $2000^{34}$ considera como secreto empresarial ${ }^{35}$ :

cualquier información no divulgada que una persona natural o jurídica legítimamente posea, que pueda usarse en alguna actividad productiva, industrial o comercial, y que sea susceptible de transmitirse a un tercero, en la medida que dicha información sea:

a) secreta, en el sentido que como conjunto o en la configuración y reunión precisa de sus componentes no sea generalmente conocida ni fácilmente accesible por quienes se encuentran en los círculos que normalmente manejan la información respectiva;

b) tenga un valor comercial por ser secreta; $y$

c) haya sido objeto de medidas razonables tomadas por su legítimo poseedor para mantenerla secreta. (Destacamos).

La anterior información que señala a título enunciativo dicho artículo puede referirse a, entre otros, lo siguiente: "la naturaleza, características o finalidades de los productos; a los métodos o procesos de producción; o a los medios o formas de distribución o comercialización de productos o prestación de servicios".

Sobre el concepto y los requisitos de los secretos empresariales ya se ha pronunciado la doctrina ${ }^{36}$, no obstante, es importante recalcar que no toda información

33 Superintendencia de Industria y Comercio. Delegatura para Asuntos Jurisdiccionales. Sentencia n. 006 del 22 de octubre de 2008, "por la cual se decide un proceso por competencia desleal”. Radicación: 03102960. Demandante: Rafael Ospina Botache. Demandado: Raos Ltda. Hoja número 7.

34 Régimen Común sobre Propiedad Industrial.

35 En México, el secreto empresarial se conoce como el nombre genérico de "secreto industrial”, que se subdivide en secretos comerciales, industriales y de prestigio. De acuerdo con el artículo 82 de la Ley de Propiedad Industrial Mexicana, los secretos industriales son toda información que (i) sea de aplicación industrial o comercial, que (ii) sea confidencial, (iii) que les signifique una ventaja competitiva o remunerada frente a terceros, y que (iv) se hayan adoptado las medidas necesarias para guardar su confidencialidad (Magana, J. M. Titularidad de la propiedad industrial e intelectual en México realizada bajo una relación de trabajo o por encargo. Revista La Propiedad Inmaterial. Bogotá: Universidad Externado de Colombia, 2014, (18), pp. 145-165. IssN: 1657-1959).

36 Léanse, por ejemplo, los siguientes libros: Товón Franco, N. Secretos industriales, comerciales y know how. Bogotá: Editorial Jurídica Dike, 2008, pp. 35-47. ISBN: 9789588235998 y Lizarazu Montoya, R. Manual de propiedad industria. Bogotá: Legis Editores, 2014, pp. 348-351. ISBN: 978-958-767-217-6. 
secreta, privada o confidencial es un secreto empresarial, porque la regulación colombiana exige que, entre otras cosas, esta no solo sea secreta o no sea de conocimiento público o de fácil acceso por las personas que trabajan en el sector económico en el cual se utiliza esa información, sino que además pueda usarse en alguna actividad productiva, industrial o comercial ${ }^{37}$. Teniendo en cuenta lo anterior, es factible que en un caso se presente cualquiera de las siguientes hipótesis: (i) que la información que la empresa considera como secreto empresarial sea información común que ya conocían otras personas debido a su experiencia profesional de varios años de trabajo en el mismo sector comercial en que participa la empresa; (ii) que la información que la empresa considera como secreto empresarial sea generalmente conocida o fácilmente accesible entre las personas vinculadas al mismo sector comercial en que participa dicha empresa y/o (iii) que la información que la empresa considera como secreto empresarial no pueda usarse o no tenga relación con alguna actividad productiva, industrial o comercial. De confirmarse cualquiera de las hipótesis, no se estaría en ningún caso frente a secretos empresariales.

Obsérvese que la norma establece los requisitos imperativos para que la información pueda ser considerada jurídicamente como secreto empresarial. Por eso, es inconsistente con la ley el catalogar a priori cualquier información como secreto empresarial. Esto llevaría al absurdo de considerar como secreto empresarial, por ejemplo, el estado de salud de un funcionario de una organización. Si bien los datos relativos de salud son datos privados y sensibles, ello no significa que también sean secretos empresariales.

\section{LAS CLÁUSULAS CONTRACTUALES COMO MECANISMO IMPORTANTE,} PERO INSUFICIENTE, PARA PROTEGER LOS SECRETOS EMPRESARIALES

La regulación colombiana exige a los administradores ${ }^{38}$ no solo "obrar de buena fe, con lealtad y con la diligencia de un buen hombre de negocios" 39 , sino que les impone el deber de "guardar y proteger la reserva comercial e industrial de la sociedad" ${ }^{40}$. El incumplimiento de estas obligaciones genera responsabilidad solidaria e ilimitada en cabeza del administrador por los perjuicios que ocasione por su dolo o culpa ${ }^{41}$. Esto obliga a los administradores a ser muy diligentes en la protección de los secretos empresariales. De lo anterior surge la siguiente pregunta: ¿son las cláusulas contractuales un instrumento suficiente para proteger los secretos empresariales?

37 Cfr. Literal a) del artículo 260 de la Decisión Andina 486 de 2000: "Régimen Común sobre Propiedad Industrial”.

38 "Son administradores, el representante legal, el liquidador, el factor, los miembros de juntas o consejos directivos y quienes de acuerdo con los estatutos ejerzan o detenten esas funciones" (artículo 22 de la Ley 222 de 1995).

39 Cfr. Artículo 23 de la Ley 222 de 1995.

40 Cfr. Numeral 4 del artículo 23 de la Ley 222 de 1995.

41 Cfr. Artículo 24 de la Ley 222 de 1995. 
El artículo 260 de la Decisión Andina 486 de 2000 exige que los secretos empresariales sean objeto de, entre otras, "medidas razonables tomadas por su legítimo poseedor para mantenerla secreta". Replicando la pregunta anterior, surge la siguiente: ¡son las cláusulas contractuales una medida razonable para mantener el secreto de la información?

La razonabilidad de las medidas depende de cada caso y obliga a implementar políticas y prácticas suficientes (cualitativa y cuantitativamente) para mantener en secreto esa información. Esas medidas pueden ser de diversa naturaleza, como organizacionales, técnicas, humanas y contractuales. Ninguna es, per se, suficiente, pero la implementación de varias de ellas contribuirá a garantizar mayores niveles de seguridad de la información.

En otras palabras, el titular de la información debe velar por que se adopten las medidas necesarias para mantener secreta información específica. Esas medidas pueden manifestarse en forma contractual de manera expresa o pueden darse de manera implícita, deducible de la conducta del empresario. En uno u otro caso, las medidas tomadas deben ser idóneas para la consecución del fin que buscan ${ }^{42}$. Lo importante es que esas medidas estén acompañadas de procedimiento, que efectivamente materialicen los niveles de seguridad en cada caso concreto y que no se trate de meras enunciaciones formales sin ninguna aplicación práctica. Por eso, lo recomendable es que las medidas sean útiles, medibles y verificables o demostrables.

Para establecerlas, se deben tener en cuenta, entre otros, las técnicas de seguridad generales y para sectores específicos existentes, los riesgos que presenten el tratamiento y la naturaleza de la información que deba protegerse, la probabilidad y severidad del daño obtenido, la sensibilidad de la información y el contexto en el que se usa. En vista de que la seguridad es un proceso dinámico en constante evolución y prueba, se quiere que exista un nivel de seguridad proporcional a la probabilidad y severidad del daño que pueda generar el acceso sin permiso a la información o su uso no autorizado.

Ahora bien, si para un empresario son importantes sus secretos empresariales, pues es sensato que adopte medidas estrictas de seguridad y no se limite únicamente a pactar cláusulas de confidencialidad de la información, por ejemplo. Desde luego que son mecanismos útiles, pero son insuficientes frente a información valiosa y crucial para la actividad empresarial. Así, por ejemplo, una cláusula contractual que exija seguridad de la información no es, per se, razonable para alcanzar dicho objetivo. Tal cláusula debe ir acompañada de otros instrumentos (capacitación a los empleados, monitoreo, control, auditorías) para verificar si las medidas son útiles, pues ninguna de ellas es suficiente por sí sola.

42 En este sentido, consultar: Restrepo, J. S. El secreto empresarial: concepto teórico y fallas a la hora de alegar su violación ante la Superintendencia de Industria y Comercio. Revista de Derecho Privado. Bogotá: Universidad de los Andes, 2013, (49), pp. 1-34 (p. 11). ISSN: $1909-7794$. 
Nótese que el artículo 265 de la Decisión Andina 486 de 2000 establece que toda persona que, con motivo de su trabajo, empleo, cargo, puesto, desempeño de su profesión o relación de negocios tenga acceso a un secreto empresarial sobre cuya confidencialidad se le haya prevenido, deberá abstenerse de usarlo o revelarlo. Esa prevención puede ser expresa o implícita, aunque esta última pueda ser cuestionada al momento de probarse. En uno u otro caso, el empleado o vinculado a la empresa que tenga acceso a la información debe ser previamente informado del carácter confidencial de tal información para que se le pueda exigir que se acoja a los deberes de reserva que surgen como consecuencia de conocer un secreto empresarial ${ }^{43}$.

Esto quiere decir que no siempre es necesario comunicarle al empleado que la información es confidencial si de los esfuerzos de la empresa se puede deducir fácilmente que la información en cuestión es de carácter reservado. De lo contrario, es obligación del poseedor de la información velar por que quienes tengan acceso a esta conozcan explícitamente su carácter de secreto empresarial.

Aunque la regulación laboral exija al empleado la conservación de secretos empresariales -específicamente en el Código Sustantivo del Trabajo, en el numeral 2 del artículo 58, numeral 6 y 8 del artículo 62, y el literal c del numeral 1 del artículo 250-, en la práctica es usual suscribir acuerdos de confidencialidad o incluir una cláusula de este estilo en el contrato laboral. En este sentido, Peña Valenzuela ${ }^{44}$ concuerda con que "mediando relación laboral usualmente se pactan cláusulas expresas en las cuales se obliga al trabajador a mantener una confidencialidad sobre determinadas informaciones conocidas o utilizadas en sus actividades normales".

En todo caso, independientemente del medio que se utilice para darle a conocer a los empleados o a terceros que cierta información es un secreto empresarial, no basta con informarles de forma genérica, sino que se debe probar que ello se hizo individualmente y que, además, se implementaron estrategias de capacitación y formación para que la seguridad en la organización sea real y medible, y no solo formal e inexistente en la práctica. Por eso, las medidas formales y abstractas no son suficientes, sino que se debe demostrar inequívocamente que la organización o empresa (i) informó individualmente a cada empleado sobre estas, (ii) le advirtió a cada empleado de la importancia de la información y su naturaleza jurídica, y (iii) lo capacitó debidamente para que cumpla de forma efectiva las medidas de seguridad.

En suma, una sociedad debe implementar instrumentos efectivos para proteger su información. Tratándose de los secretos empresariales, dichas medidas deben ser útiles, eficientes, medibles y comprobables. Esas medidas deben ser de mayor nivel de protección respecto de las utilizadas para proteger otro tipo de información de

43 Cfr. Sierra, H. Las cláusulas de confidencialidad en el contrato de trabajo. Revista de Derecho de la Pontificia Universidad Católica de Valparaíso [en línea]. Santiago de Chile: Universidad Católica de Valparaíso, 2013, (41). Issn: electrónico: 0718-6851. Disponible en http://www.scielo.cl/scielo.php?script=sci_arttext\&pid=S0718-68512013000200005

44 Peña Valenzuela, D. Nuevos alcances de los secretos empresariales en Colombia. Revista Con-Texto. Bogotá: Universidad Externado de Colombia, 2011, (9), p. 12. IssN: 0123-6458. 
menor importancia para la sociedad, razón por la cual implican exigir mayores grados de seguridad, mayores restricciones de acceso y mayores controles en el uso, más aún en el contexto actual, en el que la tecnología domina los entornos empresariales ${ }^{45}$.

\section{LÍMITES A LAS CLÁUSULAS CONTRACTUALES}

Como se vio, las estipulaciones contractuales son un instrumento no solo para exigir que la información se mantenga como secreta, sino para advertir la naturaleza jurídica de tal información e imponer obligaciones a las partes ${ }^{46}$. A pesar de lo anterior, la autonomía de la voluntad no es ilimitada, ya que el regulador busca ponerle frenos a esta con miras a proteger intereses legítimos de terceros y de la sociedad en general.

Esos intereses están expresamente plasmados en la Constitución Política de Colombia, la cual no solo ordena al Estado proteger la propiedad intelectual ${ }^{47}$ y promueve la libertad económica junto con la iniciativa privada "dentro de los límites del bien común” ${ }^{48}$, sino que clama por la prevalencia del interés general ${ }^{49}$ y la primacía de las normas constitucionales ${ }^{50}$. Todo lo anterior evidencia algunos límites constitucionales a la autonomía de la voluntad de las partes, que para ciertos autores representa un ejemplo de la constitucionalización del derecho privado ${ }^{51}$.

Pero en el escenario de la regulación de los secretos empresariales también existen límites a dicha autonomía, los cuales se derivan del propio artículo 260, que precisa las condiciones que debe reunir cierta información para ser considera como secreto empresarial. La redacción del citado artículo claramente condiciona la naturaleza de la información al cumplimiento de ciertos requisitos por parte de esta. Si contractualmente se trata de catalogar como secreta información que no

45 PAYÁn, C. Secreto empresarial, vigencia como mecanismo de protección en la propiedad intelectual. Revista La Propiedad Inmaterial. Bogotá: Universidad Externado de Colombia, 2011, (15), pp. 207-224. IssN: 1657-1959.

46 En este sentido, por ejemplo, manifiesta la doctrina que una cláusula o acuerdo de confidencialidad exige el silencio de quien se obliga para "proteger información íntima, comercial o confidencial y de esta manera salvaguardar la competitividad del negocio" (Maldonado, I. A. Validez de las cláusulas restrictivas de no competencia en el empleo. Revista de Estudios Críticos del Derecho (CLAVE). San Juan, Puerto Rico: Universidad Interamericana de Puerto Rico, 2007-2008, 3(1), pp. 115-133. Issn: 2374-6017. Disponible en http://www.derecho.inter.edu/inter/sites/default/files/revista_clave/documentos/ Revista_Clave_Tomo_3.pdf

47 Cfr. Artículo $6 \overline{1}$ de la Constitución Política de Colombia.

48 Cfr. Artículo 333 de la Constitución Política de Colombia.

49 Cfr. Artículo 1 de la Constitución Política de Colombia.

50 Cfr. Artículo 4 de la Constitución Política de Colombia.

51 Sobre este tema, véase el siguiente libro: Calderón Villegas, J. J. La constitucionalización del derecho privado. La verdadera historia del impacto constitucional en Colombia. Bogotá: Biblioteca Jurídica Uniandina, Universidad del Rosario y Editorial Temis, 2011. ISBN: 978-958-35-0808-0. 
reúne dichas características, esa cláusula -en su totalidad o en parte- sería contraria a la ley y sería catalogada como nula ${ }^{52}$, absoluta o parcial, según el caso.

Así las cosas, la naturaleza jurídica del secreto empresarial surge de la ley y no depende de la voluntad de las partes de un contrato; de ser así, se transformaría en confidencial información que es de naturaleza pública, de acceso público o generalmente conocida. Por lo tanto, en cada caso es necesario precisar en detalle cuál es la información concreta que se quiere catalogar como secreto empresarial y luego de un análisis establecer si realmente lo es.

Visto lo anterior, se puede concluir lo siguiente:

Las cláusulas de confidencialidad son un mecanismo contractual de uso frecuente para proteger cierta información importante. Este tipo de pactos contractuales son, en principio, jurídicamente válidos.

A pesar de lo anterior, esta hipótesis no es apropiada en este caso dado que no existe norma que considere ineficaz el contenido de cláusulas sobre secretos empresariales. Por eso, lo más pertinente es considerar la cláusula nula, tal como se verá a continuación.

- En primer lugar, el contenido total o parcial de las cláusulas no produce efectos porque así lo expresa algún artículo del Código de Comercio de la República de Colombia o cualquier otra norma, situación en la cual la cláusula se considerará ineficaz de pleno derecho, tal y como lo establece el artículo 897 del Código de Comercio.

- En segundo lugar, el contenido, total o parcial, de la cláusula desconoce una norma imperativa o tiene causa u objeto ilícito, caso en el cual la disposición contractual es nula total o parcialmente, como lo ordenan los artículos 899 y 902 del Código de Comercio.

- En tercer lugar, el contenido, total o parcial, no es ineficaz ni nulo, pero se refiere a información que no es susceptible de protegerse como confidencial o secreto empresarial por tratarse de información de naturaleza pública, de acceso público o generalmente conocida. En este caso puede suceder lo siguiente: (1) formalmente, la redacción de la cláusula no tiene ningún cuestionamiento jurídico, porque se refiere a información que, en apariencia, es confidencial o reservada, o (2) materialmente, la información transmitida o dada a conocer en desarrollo del contrato no es confidencial o secreta a pesar de que así se le catalogue contractualmente. En este sentido, la Superintendencia de Industria y Comercio de la República de Colombia ${ }^{3}$ ha establecido con toda claridad que "[...] el solo hecho de firmar cláusulas de confidencialidad no convierte tampoco la

52 Cfr. Artículos 899 y 902 del Código de Comercio.

$53 \mathrm{La}$ Superintendencia de Industria y Comercio es la autoridad colombiana encargada de, entre otros, los asuntos de propiedad industrial, protección del consumidor y de la competencia. Tiene facultades jurisdiccionales para decidir sobre acciones por actos de competencia desleal y procesos de infracción de derechos de propiedad industrial. Para más información sobre esta Superintendencia, se recomienda visitar su página web: http:// www.sic.gov.co. 
información en secreta, pues no puede convertirse lo público en confidencial por vía contractual"54 (destacamos). En línea con lo anterior, Metke Méndez ha argumentado lo siguiente:

La doctrina ha entendido que el secreto empresarial debe tener un elemento objetivo que justifique su protección legal y que no permita que el empresario le atribuya ese carácter a cualquier tipo de información de manera arbitraria. El secreto solo puede recaer sobre información que tenga un verdadero interés para el empresario, en la medida que le da una ventaja competitiva frente a otros empresarios por ser desconocida por estos ${ }^{55}$. (Destacamos).

En síntesis, la verdadera naturaleza jurídica de la información no se establece mediante cláusulas contractuales, sino que se determina por el cumplimiento de los requisitos establecidos por ley.

\section{LAS CLÁUSULAS CONTRACTUALES NO PUEDEN SER UTILIZADAS PARA TRANSFORMAR NATURALEZA JURÍDICA DE LA INFORMACIÓN}

Se reitera que una cláusula contractual -especialmente la de confidencialidad- no puede establecer que se considerará como un secreto empresarial aquello que por su naturaleza no cumple los requisitos previamente establecidos en la ley.

El artículo 261 de la Decisión Andina 486 de 2000, en concordancia con lo establecido previamente en el artículo 75 de la Decisión Andina 344 de 1993, no considera como secreto empresarial la información que deba ser divulgada por disposición legal o por orden judicial, la que sea de dominio público o la que resulte evidente para un técnico en la materia. Sobre lo anterior, Metke Méndez ha señalado:

[...] la información que sea de dominio público, por su propia naturaleza, no puede ser objeto de secreto empresarial, y ello se infiere de la propia definición del secreto empresarial, según la cual debe versar sobre información no divulgada. La de dominio público no solo es información divulgada, sino de público conocimiento y de libre circulación ${ }^{56}$.

Inclusive la misma Decisión Andina 486, en el inciso segundo del artículo 264, les pone una limitante a las cláusulas de confidencialidad del siguiente tenor:

54 República de Colombia. Superintendencia de Industria y Comercio. Radicación: 15-33228. Demandante: Sighinolfi Group Colombia S. A. Demandada: Indurrego S. A. S. Acta de audiencia del 27 de mayo de 2016.

55 Metke Méndez, R. Lecciones de propiedad industrial (II) Bogotá: Editorial Baker \& Mckenzie, 2002, p. 89. IsBN: 978-84-470-5216-5.

56 Metкe, R. Lecciones de propiedad industrial (II)... p. 91. 
En los convenios en que se transmitan conocimientos técnicos, asistencia técnica o provisión de ingeniería básica o de detalle, se podrán establecer cláusulas de confidencialidad para proteger los secretos empresariales allí contenidos, siempre y cuando [estas] no sean contrarias a las normas sobre libre competencia.

La limitación transcrita se entiende en el sentido de que no podrá dársele tratamiento de secreto empresarial a información que no reúna los requisitos contenidos en el artículo 260, en particular cuando la información sea de dominio público $y$, en consecuencia, no amerite protección a nivel contractual, ni mucho menos se puede transformar su naturaleza jurídica mediante cláusulas contractuales ${ }^{57}$.

A pesar de lo anterior, resulta importante precisar dos puntos. En primer lugar, todo secreto empresarial es información confidencial, pero no toda información confidencial es secreto empresarial. En este sentido, los secretos empresariales son una especie de información confidencial. En segundo lugar, las cláusulas de confidencialidad no dejan de ser importantes y útiles en ciertos casos, porque, si bien no tienen el don de transformar la naturaleza jurídica de la información en secreto empresarial, continúan siendo válidas en todos los demás aspectos respecto de información que realmente sea confidencial - pero no secreto empresarial-, y la parte que no observe lo pactado estaría incurriendo en responsabilidad contractual.

\section{VISIÓN DE LA SUPERINTENDENCIA DE INDUSTRIA Y COMERCIO SOBRE CLÁUSULAS DE CONFIDENCIALIDAD}

La Superintendencia de Industria y Comercio (sIC) reitera lo señalado anteriormente frente a la naturaleza de la información que puede protegerse como secreto empresarial en cláusulas de confidencialidad. Así, por ejemplo, en el caso Nuevas Inversiones Tecnológicas S. A. S. vs. Infobip Colombia S. A. S., la sic señaló:

La información considerada como 'clasificada y confidencial' por Nuintesa, esto es, los clientes, la infraestructura requerida para lograr la efectiva prestación del servicio de mensajería de texto, los costos para la prestación de sus servicios, no reúne los requisitos establecidos en el literal a) del artículo 260 de la Decisión 486 de 2000 y, por tanto, no pueden considerarse secretos, por cuanto en dicho artículo se establece que la información secreta o clasificada no podrá ser de aquella que es generalmente conocida ni fácilmente accesible por quienes se encuentran en los círculos que normalmente manejan la información respectiva ${ }^{58}$.

En particular, y en otra sentencia, la sic precisó:

58 República de Colombia. Superintendencia de Industria y Comercio. Radicación: 14-266450. Demandante: Nuevas Inversiones Tecnológicas S. A. S. Demandada: Infobip Colombia S. A. S. Acta de audiencia de febrero de 2016. 
La información que sustenta la acusación, por lo menos de cara a Infobip, no puede ser considerada como CONFIDENCIAL así esté estipulado en un acuerdo, por cuanto la norma es clara en señalar que eso no reúne las condiciones para considerarse secreto $[\ldots]^{59}$.

Dada su pertinencia con los objetivos de este texto, se relacionan y transcriben algunos casos de 2016 de la Superintendencia de Industria y Comercio en los cuales se recalcan, entre otras cosas, las siguientes: en primer lugar, que no es secreto empresarial toda información cobijada bajo cláusulas contractuales de confidencialidad y, en segundo lugar, que es imprescindible probar en el proceso la naturaleza de secreta de la información objeto de debate.

En el caso Sighinolfi Group Colombia S. A. vs. Indurrego S. A. S., de 2016, la acusación consistió en que Indurrego, debido a las relaciones comerciales sostenidas con Sighinolfi y por medio de los "contratos de fabricación de mobiliario comercial", supuestamente tuvo acceso a los diseños de propiedad de esta última, así como a los listados de clientes, estrategias de negocios, procedimientos industriales, datos de contacto de clientes y precios finales de aquellos, los cuales, según el demandante, usó en beneficio propio sin autorización alguna, pese a la advertencia de la prohibición de su uso realizada por medio del contrato citado.

La sIC, luego de recurrir a lo establecido en la Decisión Andina 486 de 2000 sobre la definición y requisitos que debe cumplir cierta información para alcanzar el "estatus" de secreto empresarial, concluyó lo siguiente:

"La información que SIGHINOLFI considera como confidencial no reúne los requisitos establecidos en el literal a) del artículo 260 de la Decisión 486 de 2000, por lo tanto, no se puede considerar como de carácter secreto. Esto debido a que no aparece claro en este expediente que los diseños utilizados por la demandante en el desarrollo de su actividad comercial fueran realmente secretos" ${ }^{30}$.

En el mismo sentido se pronunció sobre la información respecto de los clientes al señalar lo siguiente:

La misma suerte debe correr la información sobre los clientes, tal como lo ha dejado sentado esta entidad en varias oportunidades en donde ha señalado que, en línea de principio, la información sobre clientes y proveedores no tiene el carácter de secreta, pues los adquirentes potenciales de bienes y servicios, así como el acceso a ofertas mercantiles por regla general es de conocimiento público y de fácil acceso por medios masivos de información como la internet, a menos, claro está, que se demuestre que

60 República de Colombia. Superintendencia de Industria y Comercio. Radicación: 15-33228. Demandante: Sighinolfi Group Colombia S. A. Demandada: Indurrego S. A. S. Acta de audiencia del 27 de mayo de 2016. 
en un caso específico esa información por circunstancias especiales podría considerarse confidencial, aspecto que en este caso no está demostrado ${ }^{61}$. (Destacamos).

En el caso en comento, la sic puso de presente la necesidad de que el demandante pruebe la naturaleza de secreta de la información en estos términos:

Sobre las estrategias de negocios y los procedimientos industriales, basta señalar que no aparece acreditado que la actora contara con una estrategia específica o un procedimiento industrial específico, a los que pudiera atribuírsele un carácter secreto, ni siquiera hay una mínima referencia a esos procedimientos que pudiera valorar este Despacho a fin de darle protección por la vía del secreto empresarial. De esta manera, y, dado que la información denunciada como secreta no puede elevarse a tal categoría para que se le pudiera dar una protección de conformidad con lo dispuesto en el artículo 260 de la Decisión 486 de 2000, no se cumple este indispensable presupuesto que prevé el artículo 16 de la Ley 256 de 1996, por lo que se hace innecesario entrar a abordar la forma en que la parte demandada utilizó o explotó dicha información ${ }^{62}$. (Destacamos).

Finalmente, en este caso -Sighinolfi Group Colombia S. A. vs. Indurrego S. A. S., de 2016-, la sic precisó que, como se señaló en otra parte de este escrito, "es importante aclarar que el solo hecho de firmar cláusulas de confidencialidad no convierte tampoco la información en secreta, pues no puede convertirse lo público en confidencial por vía contractual" ${ }^{63}$. (Destacamos).

En el caso Griffith Colombia S. A. S. vs. Viscofan, y otros de 2016, se alegó que la parte demandada se ha "venido lucrando de la información confidencial sustraída de la DEMANDANTE por conducto de los trabajadores que se llevó; información de la más diversa clase, tal como datos, nada más y nada menos que listados de clientes, listado de precios, métodos de mercadeo, etc.”. La SIC concluyó que, "aun cuando LAS DEMANDADAS conocieron información de GRIFFITH, no se encuentra configurado el acto desleal de violación de secretos, justamente porque no pudo demostrarse que dicha información a la cual tuvieron acceso tuviera carácter secreto" ${ }^{64}$. (Destacamos).

Respecto de las informaciones que se consideraban secretas, la sic consideró lo siguiente:

(1) "Sobre el punto, es preciso dejar claro que, en línea de principio, la información sobre clientes y proveedores no tiene el carácter de secreta, pues los adquirentes poten- 
ciales de bienes y servicios, así como el acceso a ofertas mercantiles por regla general es de conocimiento público y de fácil acceso por medios masivos de información como la internet, a menos, claro está, que se demuestre que en un caso específico esa información por circunstancias especiales podría considerarse confidencial, aspecto que en este caso no ocurrió, pues las revistas y publicaciones contenidas en ellas, obrantes a folios 88 a 232 del cuaderno n. 4 y 1 a 26 del cuaderno n. ${ }^{\circ} 5$, muestran que la misma es de fácil acceso al ser pública y justamente por no ser este un mercado muy grande, los posibles clientes son determinables" ${ }^{65}$. (Destacamos).

En cuanto a los listados de precios, la sic mencionó lo siguiente:

Puede hablarse de dos tipos de listados, el primero es al que GRIFFITH le compra a viscofan y el segundo es al que Griffith les vendía a los clientes. Pues bien, el precio al que vende no puede ser tenido como información secreta debido a que las listas de precios a los clientes están dispuestas justamente para que sean conocidas por el público, por lo que para adquirir esa información basta preguntarla, y por eso es información que circula en el mercado necesariamente para poder ofrecer y comercializar los productos y, en ese sentido, no puede considerarse secreta. Otra cosa sucede con la información sobre el valor en el que GRIFFITH le compraba los productos a LAS VISCOFAN, sin embargo, hay que tener presente que LAS VISCOFAN en el presente caso son demandadas y por eso justamente dicha información no puede ser considerada secreta, porque es información de LAS visCofan, es decir, dicha información no es de GRIFFITH, entonces, es imposible afirmar que existe un acto desleal de violación de secretos, de sus secretos, cuando GRIFFITH demanda y acusa de dicha situación a quien le da justamente los precios ${ }^{66}$. (Destacamos).

Finalmente, al igual que los casos anteriores, la sic reiteró la necesidad de probar la naturaleza de secreta de la información:

Respecto de los métodos de mercadeo basta señalar que, como no se encuentra prueba que permita concluir a este Despacho que GRIFFITH cuenta con un método especialísimo de mercadeo, que reúna las condiciones de ser un método secreto, no puede tenerse tampoco por configurado el presente acto bajo estudio. (Destacamos).

65 República de Colombia. Superintendencia de Industria y Comercio. Radicación: 15-33228. Demandante: Sighinolfi Group Colombia S. A. Demandada: Indurrego S. A. S. Acta de audiencia del 27 de mayo de 2016.

66 República de Colombia. Superintendencia de Industria y Comercio. Expediente: 130211183. Demandante: Griffith Colombia S. A. S. Demandada: Viscofan, Industria Navarra de Envoltura Celulósicas S. A., Viscofan do Brasil Sociedade Comercial e Industrial Ltda., Viscofan CZ. S. R. O., Visdecol S. A. S. y Julián David Garcés Marín. Acta de audiencia del 14 de septiembre de 2016. 


\section{CONCLUSIONES}

Las cláusulas contractuales son un mecanismo relevante para proteger los secretos empresariales. No obstante, estas no son suficientes para proteger dicha información y no pueden ir más allá de lo permitido por la Constitución y la ley. Particularmente, no pueden ser usadas para transformar la naturaleza jurídica de la información que no cumple los requisitos que exige la Decisión Andina 486 de 2000.

La naturaleza jurídica de cierta información como secreto empresarial se deriva de que esta cumpla los requerimientos de ley y no de que se le atribuya mediante cláusulas contractuales. En otras palabras, prima la realidad material de la información sobre la apariencia formal que las partes quieren impregnarle contractualmente.

En este sentido, la jurisprudencia de la Superintendencia de Industria y Comercio ha cuestionado la praxis contractual de conferir a cierta información la naturaleza jurídica de secreto empresarial cuando esta no cumple los requerimientos del artículo 260 de la citada decisión.

\section{BIBLIOGRAFÍA}

Calderón Villegas, J. J. La constitucionalización del derecho privado. La verdadera historia del impacto constitucional en Colombia. Bogotá: Biblioteca Jurídica Uniandina, Universidad del Rosario y Editorial Temis, 2011. ISBN: 978-95835-0808-0.

Cano Martínez, J. ¿Eres una empresa digitalmente responsable? [en línea]. Bogotá, 20 enero de 2016 [fecha de consulta $1 .^{\circ}$ de septiembre de 2017]. Disponible en https://www.linkedin.com/pulse/eres-una-empresa-digitalmente-responsablejeimy-cano-ph-d-cfe

Lizarazu Montoya, R. Manual de propiedad industria. Bogotá: Legis Editores, 2014. ISBN: 978-958-767-217-6.

Magana, J. M. Titularidad de la propiedad industrial e intelectual en México realizada bajo una relación de trabajo o por encargo. Revista La Propiedad Inmaterial. Bogotá: Universidad Externado de Colombia, 2014, (18), pp. 145-165. ISSN: 1657-1959.

Maldonado, I. A. Validez de las cláusulas restrictivas de no competencia en el empleo. Revista de Estudios Críticos del Derecho (CLAVE). San Juan, Puerto Rico: Universidad Interamericana de Puerto Rico, 2007-2008, 3(1), pp. 115-133. ISSN: 2374-6017. Disponible en http://www.derecho.inter.edu/inter/sites/ default/files/revista_clave/documentos/Revista_Clave_Tomo_3.pdf

MetKe Méndez, R. Lecciones de propiedad industrial. Bogotá: Editorial Baker \& Mckenzie, 2001, p. 40. ISBN: 9789588075471.

MetKe Méndez, R. Lecciones de propiedad industrial (II) Bogotá: Editorial Baker \& Mckenzie, 2002, p. 89. ISBN: 978-84-470-5216-5. 
Monroy, J. C. Modo de adquisición originario de los derechos de propiedad intelectual. Revista La Propiedad Inmaterial. Bogotá: Universidad Externado de Colombia, 2003, (6), pp. 99-110. issn: 1657-1959.

PaYÁn, C. Secreto empresarial, vigencia como mecanismo de protección en la propiedad intelectual. Revista La Propiedad Inmaterial. Bogotá: Universidad Externado de Colombia, 2011, (15), pp. 207-224. IssN: 1657-1959.

Peña Valenzuela, D. Nuevos alcances de los secretos empresariales en Colombia. Revista Con-Texto. Bogotá: Universidad Externado de Colombia, 2011, (9), p. 12. ISSN: 0123-6458.

Remolina, N. Tratamiento de datos personales: aproximación internacional y comentarios a la Ley 1581 de 2012. Bogotá: Legis, 2013, pp. 135-144. ISBN: 978-958-767-086-8.

Restrepo, J. S. El secreto empresarial: concepto teórico y fallas a la hora de alegar su violación ante la Superintendencia de Industria y Comercio. Revista de Derecho Privado. Bogotá: Universidad de los Andes, 2013, (49), pp. 1-34. ISSN: 1909-7794.

Sierra, H. Las cláusulas de confidencialidad en el contrato de trabajo. Revista de Derecho de la Pontificia Universidad Católica de Valparaiso [en línea]. Santiago de Chile: Universidad Católica de Valparaíso, 2013, (41). IssN electrónico: 0718-6851. Disponible en http://www.scielo.cl/scielo.php?script=sci_arttext \&pid=S0718-68512013000200005

Suñol Lucea, A. El secreto empresarial. Un estudio del artículo 13 de la Ley de Competencia Desleal [impreso]. Pamplona: Thomson Reuters, 2009, p. 27. ISBN: 9788447031832.

TовÓN Franco, N. Secretos industriales, comerciales y know how. Bogotá: Editorial Jurídica Dike, 2008, pp. 63-72. IsBN: 9789588235998.

\section{JURISPRUDENCIA}

República de Colombia. Consejo de Estado. Sección cuarta. Sentencia del 9 de octubre de 1998. Expediente. Consejero ponente, doctor Daniel Manrique Guzmán.

República de Colombia. Superintendencia de Industria y Comercio. Delegatura para Asuntos Jurisdiccionales. Sentencia n. 006 del 22 de octubre de 2008. "Por la cual se decide un proceso por competencia desleal”. Radicación: 03102960. Demandante: Rafael Ospina Botache. Demandado: Raos Ltda.

República de Colombia. Superintendencia de Industria y Comercio. Radicación: 14-266450. Demandante: Nuevas Inversiones Tecnológicas S. A. S. Demandada: Infobip Colombia S. A. S. Acta de audiencia de febrero de 2016.

República de Colombia. Superintendencia de Industria y Comercio. Radicación: 15-33228. Demandante: Sighinolfi Group Colombia S. A. Demandada: Indurrego S. A. S. Acta de audiencia del 27 de mayo de 2016. 
República de Colombia. Superintendencia de Industria y Comercio. Expediente: 130211183. Demandante: Griffith Colombia S. A. S. Demandada: Viscofan, Industria Navarra de Envoltura Celulósicas S. A., Viscofan do Brasil Sociedade Comercial e Industrial Ltda., Viscofan CZ. S. R. O., Visdecol S. A. S. y Julián David Garcés Marín. Acta de audiencia del 14 de septiembre de 2016.

República de Colombia. Superintendencia de Industria y Comercio. Delegatura para Asuntos Jurisdiccionales. Sentencia n. ${ }^{\circ} 006$ del 22 de octubre de 2008.

Código de Comercio

Corte Constitucional. Sentencia T-473 de 1992

Corte Constitucional. Sentencia T-1268 de 2001

Corte Constitucional. Sentencia T-729 de 2002

Corte Constitucional. Sentencia C-336 de 2007

Corte Constitucional. Sentencia C-334 de 2010

Corte Constitucional. Sentencia T-511 de 2010

Corte Constitucional. Sentencia T-451 de 2011

Corte Constitucional. Sentencia C-540 de 2012

Corte Constitucional. Sentencia C-274 de 2013. M. P.: María Victoria Calle Correa.

Decisión Andina 486 de 2000

Decreto 19 de 2012

Decreto 1377 de 2013

Decreto 1510 de 2013

Decreto 1074 de 2015

Decreto 1494 de 2015

Ley 45 de 1990

Ley 222 de 1995

Ley 769 de 2002

Ley 1150 de 2007

Ley 1266 de 2008

Ley 1581 de 2012

Ley 1564 de 2012. Código General del Proceso

Ley 1621 de 2013

Ley 1676 de 2013

Ley 1712 de 2014 